\title{
We need to talk about digital ethics
}

Written by: Charlotte de Broglie, CEO and Founder, For the Future

Last update: 2 December 2019

Digital science and technology are at the heart of major economic, social and-in the eyes of some-anthropological shifts. That is why we need to think about the ethics of how these tools are produced and how they are used.

\section{Charlotte de Broglie, CEO and Founder, For the Future}

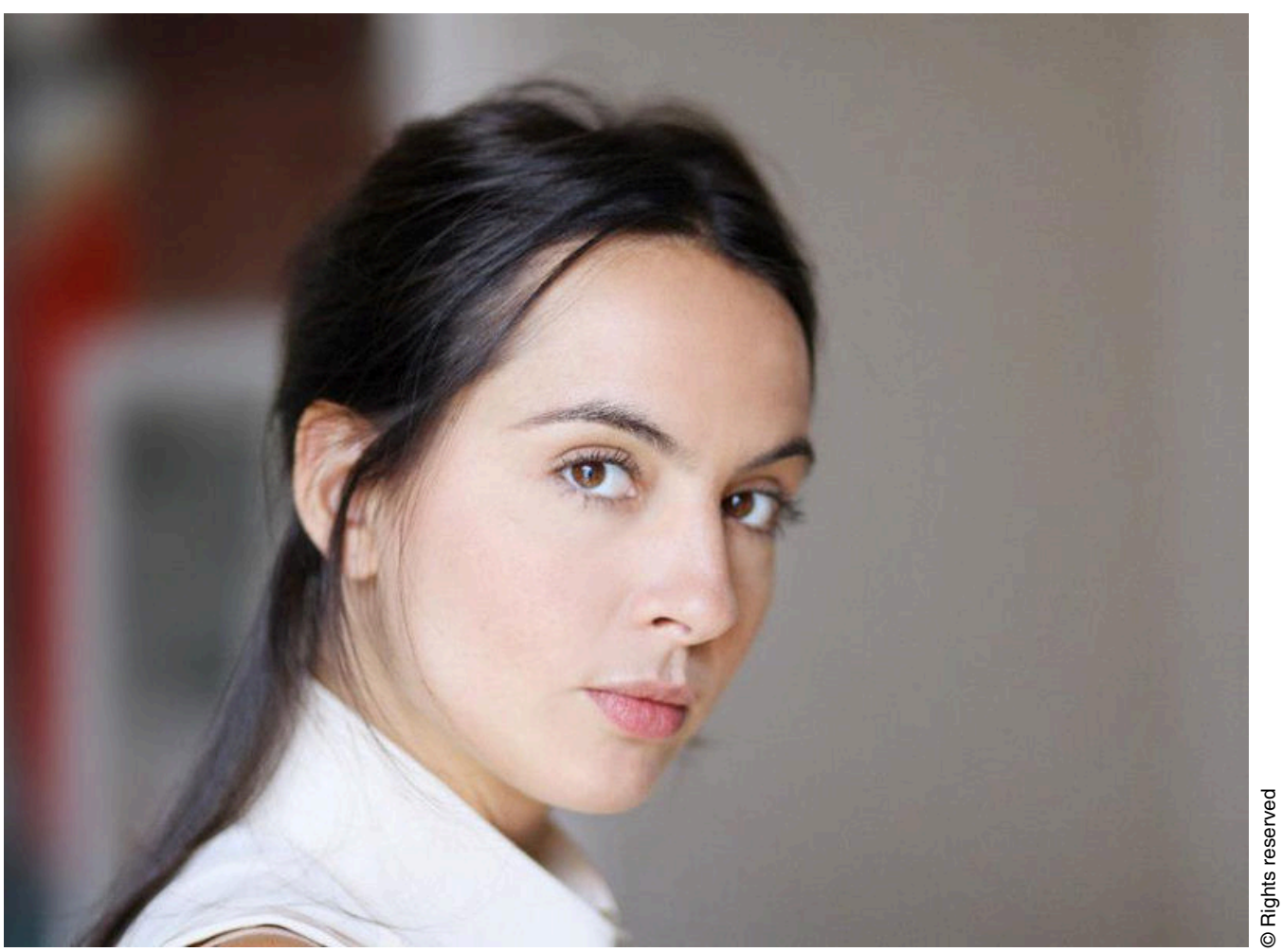

Digital technology encourages the dissemination of knowledge and know-how, but it has also helped concentrate power in the hands of both the state, through mass surveillance, and the Internet's "big four"-Google, Apple, Facebook and Amazon. Its ability to influence socio-economic structures also means it confers power and a competitive edge on those who design its applications over those who merely use them.

Indeed, it is important to realise that there is no such thing as a simple search on the Internet. In reality, all data are tracked, analysed, retrieved and reused. The impact of this can be economic, social, cultural and environmental. Just think, for 
example, of the data used for commercial and security purposes and how it infringes on people's right to privacy. Or the energy required to store data in vast datacentres.

There is an intrinsic duality to digital technology. Like the god Janus, it faces two ways, constantly turned towards both the light and the dark. It can result in the abuse of the powers of mass surveillance-think of the Snowden revelations and Wikileaks-and threaten democracies by raising the visibility of extremism. But, equally, it also help liberate oppressed peoples, as it did during the Arab Spring.

Digital technology is not neutral. Rather, it enshrines a vision and reflects a worldview. As French mathematician Nicolas Bouleau wrote, "Modelling is essentially an interpretation of a situation, an attempt a rationalisation, one of any number of plausible and conceivable possibilities." Indeed, technology does not exist outside reality, and that has never been more true than today. As a result, if we underestimate the reach of technology, we could wake up one day in a worldwide technocracy.

Yet, and despite this threat, the education of digital thinkers and creators, mathematicians, engineers, computer scientists and so on rarely addresses the ethical issues facing these digital actors, nor their responsibilities. Instead, they are presented with a utilitarian and short-term vision of the digital domain that takes little account of the broader social, economic and cultural background against which digital innovation is happening nor of its impacts. The end result is super-specialist technocrats working in isolation on the research and the development of their applications. Strikingly, the people most critical of this approach are often students themselves, who deplore the lack of a global and interdisciplinary vision in their education.

Unless digital actors, and, indeed, all citizens, are given the means to ponder, develop and foster an autonomous vision that reflects their values, we will inevitably drift towards digital autocracy. If all hope of an independent vision of digital technology is abandoned, its applications will ultimately be dictated by allpowerful multinationals, thereby strengthening their grip and adding to global imbalances, especially in the area of Internet governance.

Digital technologies are part of a bigger picture that needs to be patiently and carefully developed by theorists, scientists, engineers, digital creators and civil society in order to co-construct an empowering ethical dialogue and discourse. In the area of human-computer interaction, there can and should be a systematic ethical encounter, without slowing the momentum of innovation.

When it comes to solutions other than training, the open-source model is too often overlooked, despite the fact that universal access to source codes means that they can be verified and that, ethically, no issues can be concealed or passed 
over. The customary transparency in open-source practices means that code is subject to a genuine ethical examination, and to validation or invalidation.

Here in France, biomedical research is controlled

there seems to be an

by a national consultative ethics committee. A

similar body should be put in place for digital technology, but with a wider and more socially responsible base to ensure early and continuous monitoring of technological developments. At any urgent need to bring the concepts of responsibility and ethics in the digital arena to the forefront rate, there seems to be an urgent need to bring the concepts of responsibility and ethics in the digital arena to the forefront, in order to take the first step towards responsible innovation.

@OOECD Yearbook 2016

Visit www.forthefuture.io 